\title{
Female Football Players in England: Examining the Emergence of
}

\section{Third-space Narratives}

This paper will examine the ways in which female football players negotiate and contest gender conventions practiced in English football. I look at female participation through the application of Bhabha's 'third-space' thesis, and argue that Bhabha's work has utility in the context of this case study for understanding complexities and nuances ordinarily ignored by gendered discourse performed in English football culture. I utilise semi-structured interviewees with women who have or are still currently playing football across an age range of 17-45. I draw on a feminist 'standpoint' in order to attain narratives critical of conventional gender discourse performed in English football culture. Critiques arise in two key areas. Firstly, the impact of changes in governance under the Football Association. Secondly, the agency of players themselves to actively contest gender conventions, whether through playing football despite the negative connotations attached to female physicality, or through the provision of mixed-football.

Keywords: Third-space, women's football, gender performance, mixed-football

\section{Introduction: Gender and the English Aesthetic}

This paper applies Homi Bhabha's concept of the third-space ${ }^{1}$ to the experiences of female football players in England. I examine case study interviews to consider female participation in the context of broader transformations in English football. I focus on the ways in which women narrate their own participation and therefore the manner in which negotiated participation emerges through the course of this discussion. For example, how do female football players position themselves relative to the standardised gender discourses that frame cultural representations of the sport? Under the Football Association, the contemporary governance of football in England places a clear emphasis on the promotion of female participation. ${ }^{2}$ This would suggest that there have been significant moves towards a level of equity. However, the performance of 
gender remains congruous with conventional assumptions regarding male and female physicality. Given that the bare quantitative evidence is indicative of a greatly increased level of participation, ${ }^{3}$ the question remains as to how gender equity might be achieved by contesting the conventional gender stereotypes that inform female involvement in football. $^{4}$

I make reference in the following section to a number of issues that have amplified the manner in which gender performance bears a legacy rooted in the articulation of muscular Christianity via the playing fields of public schools such as Harrow, Eton and Charterhouse. ${ }^{5}$ I argue that gender performance in English football is subject to innovation, particularly with the emergence of an increasingly globalised football market in the latter part of the $20^{\text {th }}$ century. ${ }^{6}$ Despite consistent processes of transformation, there remains for female football players the issue that the culture of English football naturalises male performance and 'masculine' aesthetics, marginalising female physicality. For this research, the grounded experience of women within this context draws on negotiated practices of female football players and the ways in which transformations emerge.

\section{Defining the Third Space: Application to the study of female football players}

The third-space is drawn from a post-colonial theoretical tradition that seeks to examine how cultures and histories intrude on the present in the transformation of cross-cultural relations. Third-space questions the authority of dominant cultures and the continuing process of history in which the agency of the 'colonised' seek to contest dominant

discourses. Bhabha argues that interaction within culture necessitates a process of negotiation i.e. the clear distinction between coloniser and colonised is never stable and 
ambiguity, or hybridity, lends itself to patterns of transformation. This emphasis illuminates how culture changes and cultural forms or identities emerge because of this interaction.

Locating the third-space lends precedence to the borderlines of cultures (liminal) that position culture in-between familiar or 'authentic' cultural forms, consequently contesting discourses that lay claim to cultural purity. To apply such theoretical reasoning to the performance of gender in English football, demonstrates how cultural standardisation is informed by discourse that is restrictive in terms of categorising gender. In such a way, cultural complexity is neglected. For female football players this intersects with the tension between athleticism and femininity where 'mannish' female sexuality ${ }^{7}$ acquires a pejorative label through the dramatic enactment of gender performance. In terms of football, on the field of play, such discourse instigates discussion as to the manner in which gendered aesthetics are indicative of structural gender relations. In England, the development of football shares an intimate relationship between the performance of gender and the social processes that have necessitated the cultural legitimacy of a restrictive male/female dichotomy. Moreover, cultural discourse locates and solidifies football's superiority over other marginalised sports $^{8}$ and is a conduit for common sense understandings of Englishness ${ }^{9}$ underpinned by gender discourse.

'Time and time again this public school hegemony determined the course of football in the early days ... Indeed the new emphasis on football in state schools by the turn of the century was perhaps the most important factor in guaranteeing the future of football as a 
mass game and was undoubtedly a determining factor in making football the national game. $^{10}$ (my emphasis)

The teachings of Victorian Christian activism had an effectual relationship with rigorous masculinity and demonstrates how public schools utilised sport, and specifically football, as a means with which to introduce the moral characteristics attributable to 'new manliness' essential to the continuation of Britain's imperial prosperity. ${ }^{11}$ The embedding of gender duality was particularly resonant in muscular Christianity and allied to the pedagogy of Empire. For example, the ethos that football and sports in general drew upon the biological conceptualisation of the active male allied to British imperial expansion. ${ }^{12}$ McLintock discusses for example, how the extension of British Imperialism and conquering of 'virgin lands' was part of an expansive process. ${ }^{13}$ Such subjugation of passive femininity underpins the encoding of muscular Christianity through football. As cited by Walvin, 'sports, disciplined games, all were part of late Victorian and Edwardian manliness which were proof of British superiority. ${ }^{14}$

Muscular Christianity features prominently in terms of gender and English football culture. ${ }^{15}$ Physicality and heterosexual athleticism underpin discourse by which hegemonic masculinity is utilized as a proxy for competitive advantage. ${ }^{16}$ For English football, the emphasis on physicality as the desirable trait to possess bears a strong relationship to demonstrable 'heterosexual' identity. Consequently, for female football players there emerges a debate in which women who play 'male' sports endanger 'normal' sexualities. Physicality and femininity are perceived to be incompatible, and as such, cultural discourse articulates fear of active femininity because it is in contrast to passive female sexuality that signifies 'heterosexual failure.' ${ }^{17}$ For example, in terms of 
the legacy of Victorian attitudes to physical exercise, the objectification of femininity is specifically linked to the display of heterosexuality as evidenced during the early part of the twentieth century. Female participation in physical exercise was limited to sports that were considered 'suitable' to the female physique, and in physical education, forms of moderate exercise practised were "carefully monitored for masculinising effects. ${ }^{18}$ In the context of women's football this is a critical argument. Such a male/female gender duality underlines the constructed nature of gender, woman and man as political and social categories. ${ }^{19}$ They are arbitrary constructs, but given credence via biologically determined standards in gender display. With the emergence of football as a popular sport, and the dissemination of physicality as an integral facet of English football culture, ${ }^{20}$ the emerging working class were subject to moralising guidance of the civic bourgeoisie. ${ }^{21}$ In the context of an expanding capitalist industrial economy during the late $19^{\text {th }}$ century therefore, it becomes apparent that performing football is informed by a cultural disposition that bears a contingent relationship to conventionally ascribed gender roles.

\section{Epistemological and Methodological Considerations}

In order to account for female resistance in the context of gendered performance that negates female physicality, I extend the conceptual basis of the third-space by adopting a feminist standpoint. ${ }^{22}$ Female narratives drawn from a standpoint position intersect with the examination of the third-space because they question the conventional gender discourses ordinarily articulated through participation in football performances. To what extent does the application of a third-space theoretical position re-codify 'traditional' gender identities stemming from discourse rooted in muscular Christianity? To refer to Harding's 'standpoint', gender discourse performed through football is 
subject to examination utilising interviews as critical narratives that challenge our sense of 'historical identity." 23

'The intervention of the Third Space enunciation, which makes the structure of meaning and reference an ambivalent process, destroys this mirror of representation in which cultural knowledge is customarily revealed as an integrated, open, expanding code. Such an intervention quite properly challenges the historical identity of culture as homogenising. ${ }^{24}$

Adopting a critical stance that uses personal biography and subjective experience is indicative of the manner in which 'productive prejudices ${ }^{\text {'25 }}$ can generate narratives that are a critical tool in investigating the contested nature of culture. They are narratives that contest and redefine the limits placed on gender performance, because they illuminate the rigidity of binary gender categorization ${ }^{26}$ by drawing on the subjective experience of women as a critical voice to contest the objective construction of gender. ${ }^{27}$ In such a way, Bhabha's third-space enunciation articulates the potential to oppose conventional gender constructs and pursue a critique that brings into question the limits placed on women to engage in physical activity. Such epistemological reflections enable us to take into account the displacement and/or replacement of ascribed identification, ${ }^{28}$ and utilise the capacity of the social actor to interpret and negotiate questions of power and gender. ${ }^{29}$ In such a way, the narratives generated through the following discussion emphasise the capacity of the social actor to instigate change. Moreover, in order to critically engage the cultural production of gender in football, this epistemological focus is intended to communicate women's sense of belonging in a context that has traditionally sought to marginalise and exclude female football players. ${ }^{30}$ In identifying a 'sense of tradition' for women's football, ${ }^{31}$ the reflexive 
subjectivities of women who participate in football are examined in the context of the discourse that legitimises hegemonic masculinity and the marginal position of the feminine 'other'.

This study utilises semi-structured interviewees with women who have or are still currently playing football across an age range of 17-45. Whilst the context of English football is an overall frame of reference, the interviews position respondents' at a point of critical subjectivity. Members' practice is the main point of interest, and what members do that is recognisable in the production of 'observable conversation' is a starting point for enquiry. ${ }^{32}$ This is important in establishing female perceptions of the game and in eliciting the production of local knowledge in order to attain a critical view of English football culture.

\section{Transformations}

Certainly, the relationship between structure and action on the football field share a tangible relationship, but how these are contested and subject to transformation is the principal question addressed by female participation. Football cultures are varied and complex in both spatial and temporal terms,${ }^{33}$ and while it is beyond the scope of this paper to discuss at this point, change is notable because it is indicative of contestation. Change may be brought about in differing ways, as cited, through governance, but also the agency of the social actor to engage in the transformative process. ${ }^{34}$

It is notable that when examined in a global context, critical reflections on football reveal the temporal and spatial facets of culture. Through the process of globalisation, clubs, nations and continents encounter other 'exotic' football styles that 
intersect with the emergence of new and varied styles of play and many football styles have 'foreign' cultural influences. ${ }^{35}$ The freedom of movement afforded to players post$1995^{36}$ and emergence of a single football market have facilitated player migration. ${ }^{37}$ This is significant because, the ramifications for an 'English aesthetic' are tangible. Winner discusses 'sexy football' ${ }^{38}$ and the impact of foreign players on English football following the Bosman ruling.

'The overall quality of the English Premiership has risen sharply in recent years as an army of clever foreigners have helped club football throw off its baggage. But it is still far too early to see where this process will lead or whether it will fundamentally affect the English themselves. ${ }^{39}$

Furthermore, the introduction of rule changes by FIFA have sought to sanction more heavily the committing of fouls such as the 'tackle-from-behind.' ${ }^{40}$ Consequently, rules governing player behaviour intersect on the field of play and create conditions that favour skill over physicality. Witt's study conducted over two seasons found that 'players substitute from an eligible (bookable) offence toward non-eligible crimes. ${ }^{41}$ Rule changes governing tackling is based on the idea that it is dangerous. In terms of gender, it resonates in biological determinism that considers such 'roughhousing' is unfeminine behaviour. While there remains a nascent undercurrent that fortifies such gender stereotypes, with the number of female football players increasing ${ }^{42}$ there are indications that conventional gender discourse; where sexuality is used in a pejorative manner; is subject to challenge. For instance, there are idiosyncrasies expressed in the following interviews that emphasise female agency as part of the process of transformation and emergence of a more androgynous paradigm. The 'othering' of female football players then, enables recognition of disparities from which can emerge 
issues of 'third-sex' ${ }^{43}$ involvement that transform the relationship between the display of heterosexuality and hegemonic-physicality. Moreover, in terms of gender performance, the manner in which women themselves narrate their own participation, deems the space of the football field as a site for cultural struggle integral in negotiating the negative connotations associated with female physicality. With epistemological and contextual reflections in mind, during the course of the research it became apparent that the sample of women interviewed did not judge their participation as a pre-determined paradigm. Although they acknowledged conceptually rigid discourse common to English football culture, they also subject it to uncertainty from which there emerged new meaning. In short, interviewees can act as agents in cultural transformations. This analysis contends that cultural binaries are inadequate reference points, and neglect the transformatory processes that can occur when dominant and marginalized cultures meet. As such, there is a process of change reflected in the following sections.

\section{Female Football Players and the Emergence of Third-Space Narratives}

The following transcript is taken from interview and guides us through Grace's first experiences of playing football. She considers the extent to which women's football could have a sustainable future. While she acknowledges the conventional gender stereotypes performed in English football, there is quite clearly a process of change that emerges from her assessment as to the sustainability of women's football within a culture that gives precedence to male participation. Firstly, she identifies the discourse that gives context to her participation. The obligatory 'swapping shirts' comments for example, that indicate the sexualisation of women in sport, and which negates the physicality not congruous with the performance of heterosexual femininity. She contests this, a vulgar commentary that is dismissed, 'it was always sort of stupid things 
that we used to encounter, but we just laughed them off really, was the whole thing of, I guess the kind of sexism that girls get when they're 15 or 16 years old anyway, you know, 'I want to see you all swopping shirts at the end of the game', you know, stupid stuff.' Yet despite this, the following exchanges demonstrate a process of negotiation of which she is centred.

Grace: And I, at matches, you know, boys used to come and ask me for my autograph and stuff like that, phenomenal, it wasn't .... I don't remember that many girls actually being part of it, but boys were willing, I mean they obviously had some sort of respect for what we were doing which is quite a big thing, really, 20 years ago, given the attitudes you know, 'these are girls that are playing.

This is a notable assessment in which Grace demonstrates patterns of contest and negotiation revealed through her own position as a football player. Although she references patterns of exclusion ('sexism'), she also subjects dualist-gendered discourse to critical examination apparent on the part of male autograph hunters; 'boys used to come and ask me for my autograph.' Grace also expresses a muted 'respect' through a process of negotiation, which becomes apparent as she assesses her own role as a female football player. For example, Grace places her experiences in a contemporary context, and consequently recognises a process of change.

Grace: First of all, whenever we played a game we always had a crowd and most of that crowd were men and boys, and they enjoyed watching, and that was 20 years ago, so I can't see any reason why that wouldn't have gotten better over the years and attracted more and more people to it, and become something that people where it's no longer that much of a novelty. 
The dictates of third space enunciation is underpinned by the thesis that the opening of 'new spaces' is not simply the merging of disparate cultural identities i.e. male and female as oppositional constructs, but the emergence of something new. In such a way, for female participation to contest the cultural boundaries placed on female athleticism and performance, I extend the argument that categorising the relationship between gender performance and football is counter-productive. Certainly, there are practical factors such as resourcing that impinge on the development of the women's game, but female participation extends a challenge to pejorative definitions of female athleticism because it seeks to recognise participation based on ability as opposed to gender. For example, in the following interview, Linda examines the extent to which the employment of the label 'football' as a general term (as opposed to 'men's football' and 'women's football') is of benefit for the women's game in terms of its long-term structural development. How does the cessation of the Women's Football Association in 1993 for instance, have discernable connotations not only for development, but also the application of dialectical labels to what is for all intents and purposes, the same game? She takes care to emphasise that the process of labelling i.e. women's football or men's football, uses the label 'women' as a pejorative, it is othered in this process.

Linda: So the Competitions Department runs the FA Cup in the same way as it does the men's FA Cup, the development of the national game runs women's in the same way as it does for men's football. 
The fundamental question of whether the distinction between men's and women's football should be drawn are central to her assessment. There is a tension aroused by Linda's understanding that labelling football in terms of gender is detrimental to developing the women's game. Gender stereotypes are constructed as configurations in a dichotomous hierarchy and as such are powerful symbols of normalised heterosexual bodies. ${ }^{44}$ Such theorising effectively undermines individuals as active agents in defining culture, but the conceptual focus of third-space narratives locate culture, English football culture, as developing and pliant. The capacity of social actors to generate 'new knowledge ${ }^{45}$ positions female participation in a circumspect way. For example, women's willingness to engage in cultural practice that denigrates female athleticism indicates that we may take some critical distance and contest gender convention. Grace cites the problematic nature of categorising sport as gendered.

Grace: I don't really understand that (football as a 'masculine' sport), still don't understand that, because it doesn't seem, I suppose I don't really understand feminine and masculine characteristics anyway, I don't understand what the difference is, but certainly I don't think football is a sport that should be closed, that has any rational reason for being closed to women, it is a matter of thinking and it is a matter of skill. There are different ways of playing football.

She draws on the construction of masculinity, questioning its representation in the football arena. The recognition of boundaries is helpful in contextualising such responses, 'there are different ways to play football' or 'I don't really understand that (football) as a 'masculine' sport.' In this way, she rejects the notion that the category of woman and man are fixed by some condition that connotes physicality. I have explained that sectioning gender as polarised constructs is conceptually inadequate in 
accounting for not only the development in football cultures per se, but also complexity within these categorisations themselves. The categories of woman and man are prescriptive, a point that Butler articulates because they fail to take into account 'the multiplicity of cultural, social and political intersections.' ${ }^{46}$ To refer back to Bhabha regarding the mutable quality of culture, the questioning of 'authority' is intrinsic to this analysis:

'It is only when we understand that all cultural statements and systems are constructed [ ] that we begin to understand why historical claims to be inherent originality or 'purity' of cultures are untenable, even before we resort to empirical historical instances that demonstrate their hybridity. ${ }^{, 47}$

On a more practical level, the critical position of both Andrea and Brenda is not mitigated in their analysis of the scope of long-term opportunities for female players and managing expectations. ${ }^{48}$

Andrea: The girls don't have all those expectations, because it's not part I don't think it really is something they've thought about, it's not something they've seen at the moment, because it doesn't exist at the moment, and until it really starts to kick in and exist I don't really think they'll have those expectations.

Brenda: I think it'll take a long, long time, I think even if you get the professional league, it'll still be a long time before it can sustain itself to anything like the men's game, and in the football world there's still a lot of men out there who obviously will watch, but I don't think they'll watch the women's game as much, because they're expectations and their 
traditional view of it are that women shouldn't play football. It's going to take a long long time to change attitudes.

This is quite a candid assessment of the aspirations of female players. Both respondents acknowledge the affective relationship English football culture shares with the performance of heterosexual masculinity, but there is implicit reference to the scope of culture as developing and pliant. It becomes apparent during their assessment of opportunities for girls that expectations are linked to the level of structural development. This relationship demonstrates how the broadening of opportunity has tangible ramifications at a grounded level and it is indicative of the affective relationship governance has to the testing of conventional gender discourse. Consequently, the focus of governance in facilitating the development of women's football preceded valuable discussion with regard to mixed-gender football that provides a great deal of scope in which to examine the emergence of third-space narratives and distinctive performances in English football.

\section{Disrupting Gender: Third-Space Narratives in a Mixed-Gender Setting}

The capacity of bodies such as the Football Association (FA) to allow mixed-gender football is examined by firstly referring to the legal framework that governs physical education. The Theresa Bennett case highlighted conventional prejudices with regard to female participation in football. Teresa Bennett vs. The FA set the legal context for the expansion of mixed football ${ }^{49}$ and highlighted the necessity in an educational context to make football (and sports in general) more accessible via change in legislation. Although the Sex Discrimination Act (SDA) was intended to foster gender equality, Section 44 of the Act is an exemption clause that has disadvantaged women. It refers to activities where strength, speed and physique are important, therefore, it sanctions the 
banning of mixed competitions. Consequently, this clause has always been used to argue that females, because of their physiques, should not be allowed to play against males ${ }^{50}$ 'they (females) have not got the strength and stamina to run, tackle, to kick and so forth. ${ }^{51}$ Certainly the ruling in the FA's favour is underpinned by assumptions with regard to the physical capabilities of girls and boys, but by its very nature fortified difference as opposed to focusing on frameworks for challenging such stereotypes. Comparison with other European countries demonstrates the extent to which football provision in England has been lacking for girls. For example, both Norway and Sweden do not have any restrictions at all, in Germany mixed football is allowed up to under17s and both Denmark and France allow mixed football up to under-14s. Therefore, there have been fewer opportunities in England for girls to develop as football players in critical formative years. ${ }^{52}$

There is initiative within the FA to graduate the level at which girls and boys are allowed to mix. During the 2007-8 football season, the FA agreed to conduct a number of mixed gender trials that were evaluated by Brunel University in order to determine key issues involved in mixed gender football. The season 2011-12 saw the fruition of these trials with the age cap extended up to under-13 (an increase of two years). ${ }^{53}$ One important point indicated by Brunel's report is that mixed football would offer girls opportunities for skills development. ${ }^{54}$ On a structural level, this further demonstrates the importance of governance in expanding the scope of the game that allows physicalist assumptions to be tested. ${ }^{55}$ The sanctioning of mixed-football on this level, contests conventional gendered discourse at a grounded level, as discussed in the following tracts, and arguably, the mixed participation of girls and boys reveals the contestation of categorical gender boundaries. Categorical gender definition is limiting, 
it reflects the rigid boundaries that manifest social anxieties regarding 'active' female sexuality $^{56}$ and when employed as a discourse, undermines women's capabilities as football players. However, in a mixed setting I assert that the direct contestation of such social anxieties that emerge with regard to female physicality and sexuality, is apparent and manifest in revealing gender categorisation as much more complex than articulated in broader cultural representations of femininity and masculinity. Conceptually, 'third sex' diverts away from ontologically objective constructions by means of grounded social practices that 'set them apart. ${ }^{57}$

As the following interviews illustrate, the capacity of football to perpetuate ascribed social relationships has its limits tested as a result of the interactions in some informal mixed training sessions. Expectations with regard to the production of normative gendered bodies and performance may persist, but the extent to which these are constantly being redefined is open to question. Andrea shows how masculinity and femininity manifest in gendered space are subject to uncertainty, negotiated and positively contested in mixed football.

Andrea: And you can see when they do mix, the lads at first are quite responsive to the girls because they're good players, you know, and they will pass them the ball, the lads are really good with the girls actually, they don't underestimate their ability, because we've got some really good players that can show them that 'hang on, I can meg you when I want, and I can go round you when I want and I can shoot well'. So the lads here are actually quite good, but I think it's because they're getting opened up to it. And they'll ask how we're getting on, so again it's changing attitudes at that stage. 
Andrea illustrates a conflict between essentialised gender discourse and the capacity of female players to redefine the normalised gender expectancies. For all intents and purposes, a mixed setting is used to organise and recognise the extent to which new spaces are opened up, allowing opportunity for distinctive performances. Regarding non-contact and the impact of rule changes cited previously, this is typically resonant within the account below. There is reference to the impact of rule changes and the extent to which structural development (governance) intersect with the grounded experiences of female football players. Andrea certainly contextualises her discussion here in terms of the effective role that the governing body has in creating conditions that enable an inclusive and flexible approach to the development of women's football. Underpinning this analysis I would suggest that her response reveals the opportunity for social actors to break social taboos that can have a sustainable influence.

Andrea: As the skill comes into it, the more and more it will because players will hold off each other. They won't try and just break each other's legs.

This is indicative of the opening of new spaces that exhibit themselves because changes in the laws of football act as a stimulus and she suggests that the eminence of conventional gender performance is subject to change. Conversely, subscription to tradition is also apparent during this discussion.

Andrea: The girls I think would struggle in a lads game, if you match them up, it's all about matching them up if they've trained to the same extent, I think, then there are physical barriers to the girls, they're not as strong as the lads, no matter how hard they'll train. 
Such an analysis by Andrea draws on conventions with regard to male and female physical capability, but is based on established gender discourses manifest in English football. However, this misses the point that girls are disadvantaged due to a number of factors including not only simplistic gender constructs (culture), but also opportunity to play on a frequent basis and development competent skills (governance). Although mixed-football can be a vehicle to the future development of female players, a resultant synthesis of men's and women's football is not necessarily the endgame, but rather, an opportunity to break the cultural mores that inform education where girls were 'forced to play traditional female sports, ${ }^{58}$ and therefore open opportunities for girls to develop more accomplished football skills and awareness. It signifies the level at which governance effects cultural production and the historical legacy that links an individual's ability to display normalised heterosexual gender types. In such an analysis, ability to play football well is not a biological given, but is subject to systems of cultural meaning practiced in sport. Mennesson for instance, addresses the issue of masculine and feminine aesthetic in sport and considers the potential of female participation to create new identities in this framework.

'Female footballers present their sport as being more tactical than the male game, since it is based on technical mastery rather than physical strength - though this has still to be objectively proven. ${ }^{59}$

The creation of new avenues of expression, or 'third-space' narratives that demonstrate the pliable nature of culture, in the following accounts are indicative of how female participation may do this. In response to questioning regarding mixed 
football, Brenda discussed how a standardised set of rules and codes of conduct intersect with how football (using the example of hockey) may be subject to transformation.

Brenda: It's an amateur opinion, but having come through the hockey world, I can't see why you can't play. You'd have to view it in a totally separate light, from viewing a men's game or a women's game, but hockey has been one of the sports that's had a mixed game almost since the establishment of hockey. The establishment of hockey was around 1884, but I mean it's set up in a team of eleven, you've got to have six men, one of whom has to be the goalkeeper, and five women, obviously the keeping side of things, the ball is a bullet really, and it's viewed as ... although women are starting to kick over at that one, you have to learn a different game, because the sort of arrogant men turn out with five women who just run round the field and look pretty in their eyes and they do all the work. The really successful mixed teams are the ones who actually use the women. I think there's a place for that in football.

The question of mixed football is significant in terms of drawing out the direct comparisons between male and female players. Although Brenda draws on normative expectations with regard to a dualistic understanding of gender, there emerges from her analysis acknowledgment of third-spaces practiced through means of negotiation and contestation of simplified dual gender constructs directly in the context of mixed sports. There is an interesting rationality that underpins such an assessment, which lends a framework to the emergence of third-space narratives and practice of complex sexualities. The issue of mixed (sport) is engaged through consideration of precedence, and the normalisation of playing sport in a mixed gender setting, 'you'd have to view it in a totally separate light.' Precedence is a definitive factor, and for women's football 
this is a notable assessment. In seeking to contest assumptions with regard to female physicality, Brenda alludes to a process of negotiation which is integral to mixedhockey, 'the really successful mixed teams are the ones who actually use the women. I think there's a place for that in football.' In her analysis of the possibilities for women's football, mixed football opens opportunities to overcome negative connotations allied to female physicality.

In a third-space analysis, new spaces are the primary focal point. Thus prescriptive gender categorisations are shown to be subject to contestation, opening new arenas in which female participation and ability may be credited and recognised. The following narratives engage gender dualism in order to question conventional gender performances. Each respondent considers their own participation as a player in a demanding manner, consequently grounding their own experience in a confrontational way. Moreover, Thing concludes that female participation as players can be perceived as a 'liberating' experience that represents limited breaks in social taboos.

'The aim here is to undo the dichotomy in the thinking of emotions in sport and to undo the naturalness and exclusivity of the constructed relation between masculinity and femininity and aggression by illuminating how women experience and cope with aggression and competition in an elite sport setting. ${ }^{60}$

In the following set of interviews, coping mechanisms emerge as substantive means of contesting dualistic gender narratives in a mixed setting. Interviewees are seventeen years old. They recognise the physiological boundaries normalised in gendered discourse, but consider their responses to questions of playing mixed football 
with boys in training and five-a-side matches. Hannah discusses mixed football in relation to physicality, yet this is contested by Meghan's response to the same question as they discuss the benefits of mixing in terms of their own development as players. The boundaries are inconsistent, and they fluctuate between an aversion to overly aggressive play yet, conversely, recognise the benefits of mixed session that enables them to develop and attune competitive facets of their own play.

Hannah: We mix when we play here. ${ }^{61}$

Laura: We do it for charity.

Meghan: Yeah, it's not that bad, they (the boys) usually go easy. It's like five asides.

Hannah: It depends who you're playing with really. I don't think it should be allowed because lads get more aggressive, they do don't they?

Laura: Yes. It's not that bad though.

Hannah: You improve your game more because you play faster, because they play really fast don't they? It's literally, just two-touch football.

Meghan: Boys football is definitely faster.

Laura: I think girl's football is more skilful.

There is a notable juxtaposition between facets of ascribed gender convention; 'the lads get aggressive,' and contest, 'it's not that bad (mixed football).' Drawing the discussion back to Cahn's figure of the stigmatised 'mannish lesbian athlete, ${ }^{62}$ the direction which these interviews took are most notable for manner in which each of the young women explained their capacity to overcome the underlying tension between female athleticism and physicality manifest in these narratives. The matches cited in these tracts are not reference to full 11-aside matches of course, but it is notable the adjustments made within this environment, the benefits them in terms of developing their own skills for 
example. During the course of this interview, they remonstrate with each other and engage in a narrative that belies the connotations that ability to play football bears a natural relationship to hegemonic heterosexual masculinity.

Meghan: They didn't like me, on the Thursday, Friday they didn't like me, but on the Monday when we actually played football, they shut up then 'cos we showed them what we could do. We did though, didn't we?

Laura: Yes.

Meghan: They were alright after that because I don't know what they thought but.......

Laura: They tried doing all their tricks 'round us, then as soon as we put our foot in tackled them, they soon changed.

Meghan: I think when they realised we weren't there just to mess around.

Laura: That we were there to play football, and we could kick a ball, as soon as we took one on, then they started passing.

The value of agency in these accounts enables an examination of players own capacity to take part in the transformation process. The respondents begin from a point of disagreement concerning physicality to consensus on their own capacity to assert their ability as football players. The body and aesthetic in English football culture are produced through the relations of power, but the subjectivity of these female players and how they engage in football does not seem to be experienced as conflict between their own ability to perform gender and their role as football players. Rather, this is experienced as a site of emancipatory conflict. This in many ways demonstrates the importance of adopting a standpoint in enabling the production of third-space narratives. The naturalised ability of these players is confounded by their discussion of 
their own skill and aptitude in directly confronting normative assumptions about what the female body is able to do within such an environment.

Overall, what female footballers show us is that, in recognising the barriers to female participation, male/female gender performance can be contested and positively transgressed culminating in transformation. In this way, it is a form of resistance. The teaching of team skills in conjunction with boys, for example, resonates in theories of transgression. ${ }^{63}$ The resultant narrative instigates and develops this analysis further.

Andrea: We don't really train together, but sometimes like if there are small numbers for training, an example was that on Monday we had small numbers for training, we went inside and we did like a 2 v 2 head tennis, very tight skills over the net, volleying, it's not physical contact with each other, it's your own skill, but there are mixed teams, so a lad and a girl were together, you know volleying to each other, it's like volleyball really, and I suppose there is a little bit like that where it's very tight skills. ${ }^{64}$

In short, female football players can demonstrate how English football culture is multiplicitous and displays temporalities, and as such are extremely contested spaces. Such a position of critical ability presents a challenge to gender convention as practised in football as the active defining element in a sport that marginalises female participation. As such, the application of third-space positioning, seeks to examine binaries e.g. man/woman, heterosexual/homosexual etc, and offers the possibility of re-defining such categorisations and open up new spaces. It is a form of cultural resistance, and the application of a standpoint in which female activities are situated in 'male' contexts, positively contest categorically defined gender constructs. 


\section{Conclusion}

In conclusion, the extent to which there is scope for the participation of female football players to contest the broader gendered discourse articulated and performed in English football, is underpinned by the application of an epistemological position that utilised female narratives. With the application of a critical analysis using female subjectivities, the utilisation of such a standpoint framework ${ }^{65}$ is fundamental in examining the extent to which female football players evidence new and emerging identities in a context that has traditionally marginalised their participation. Consequently, social location is important in this analysis. Female subjectivities demonstrate the ways in which English football culture may be disrupted from both a structural perspective and at a grounded level. In such a way, the emergence of a third-space position addresses concerns about the extent to which female participation at a grounded level disrupts objectified constructs of female performance in physical activity. Moreover, aesthetic transformations that emerge in a global football context, continually informs the character of the English game, and in such context, one may conclude women's football is also informed by this process of change. What is important for female footballers is to overcome the 'constraints' imposed by gender convention tied to femininity and physicality. In terms of this case study, the value of women's own accounts in negotiating practices forms a fundamental part of this process. In contesting dominant gender discourses, the 'naturalised' dichotomous male/female discourse indicates the capacity of women to assert their own ability. As Bhabha cites, culture and cultural knowledge is 'an integrated, open, expanding code. ${ }^{66}$ As such, the third space thesis enables us to examine the polysemic nature of football cultures, and the extent to which female participation disrupts conventional gender 'performances' i.e. the capacity of the social actor at a local level to instigate change. From the narratives that have been 
investigated during the course of this paper, opportunity would seem to derive from moves at the level of governance in increasing opportunities for female participation. Certainly, in the progression of transitional structures, e.g. the formation of the Women's Super League, the opportunity for women to compete and transform gender conventions is facilitated. Such opportunities have enabled women to actively engage pejorative constructs regarding female performance in football. This is most notably asserted through the narratives of the younger female players, and it would suggest that a mixed football setting is a positive environment in which to contest stereotypical gender constructs. However, the process of transformation in English football would seem to lie in a co-ordinated effort through the modification of England's governing structure and most importantly, the expulsion of myths regarding female physical capacity. 

1 Bhabha, The Location of Culture, 54

2 The FA announces intentions to promote women's football, FA announces five-year plan to boost women's football, http://www.bbc.co.uk/sport, $25^{\text {th }}$ October 2012, accessed $4^{\text {th }}$ October 2013

3 Since the development of women's football came under the remit of the FA and consequent cessation of the WFA in 1993.

4 SKY Television's Andy Gray commented on referee's assistant Sian Massey prior to a match between Wolves and Liverpool (2010-11), "Can you believe that? A female linesman. Women don't know the offside rule," said Gray. Both Gray and his co-commentator Richard Keys were later sacked.

5 Leisure pastimes are a social commentary 'a story they tell about themselves' from Geertz, Deep Play: Notes on the Balinese Cockfight, 448

6 Giulianotti and Robertson, Globalisation and Football, 63

7 Cahn, Coming on Strong, 165

8 See Lipset and Rokkan's ‘frozen space’ in Markovits and Hellerman, American Exceptionlism, 19

9 Walvin, The People's Game, 22

10 Walvin, The People's Game, 44; Winner, Those Feet: A Sensual History of English Football, 6-40

11 The social purity movements that came from this warned of the dangers of 'that horrible thing done in secrecy' in Winner, A Sensual History of English Football, 20-21, 9. Also in Walvin, The People's Game, 40

12 Williams and Woodhouse, Can Play, Will Play? Women and Football in Britain, 7

13 McLintock, Imperial Leather: Race, Gender and Sexuality in the Colonial Contest, 29

14 Walvin, The People's Game, 15 
15 Winner, A Sensual History of English Football, 16

16 Buzuvis, Caster Semenya and the Myth of a Level Playing Field, 37

17 Cahn, Coming on Strong, 165

18 ibid, 8

19 Stanley and Wise, Breaking Out Again: Feminist Ontology and Epistemology, 21

20 Wilson, Inverting the Pyramid: A History of Football Tactics, 26, 39

21 Giulianotti, Football: A Sociology of the Global Game, 5

22 Harding, Whose Science? Whose Knowledge? Thinking from Women's Lives, 119

23 Bhabha, The Commitment to Theory, 20

24 Bhabha, The Location of Culture, 54

25 Gadamer quoted in Prasad, Crafting Qualitative Research: Working in the Post Positivist Traditions, 33

26 Butler, Performative Acts and Gender Construction, 402

27 'Strong objectivity requires that we investigate the relationship between subject and object, rather than deny existence of, or seek unilateral control over this relation' in Harding, Whose Science? Whose Knowledge? 151-152

28 Ikas and Wagner, Communicating in the Third Space, 2

29 Sandvoss, Fans: The Mirror of Consumption, 6; Fiske, Understanding Popular Culture, 168

30 The FA ban on women using facilities of affiliated clubs from 1921-1971 
31 Williams, A Rough Game for Girls? A History of Women's Football in Britain, 68

32 Hester and Francis, Doing Data: The Local Organisation of the Sociological Interview, 36

33 see Giulianotti, Football: A Sociology of the Global Game; Giulianotti and Robertson, Globalisation and Football; Wilson, Inverting the Pyramid

34 Giulianotti, Football: A Sociology of the Global Game, 140. Termed 'street kid geniuses'

35 ibid, $141-142$

36 The Bosman Ruling effectively increased the movement of players of football associations in the European Union subject to governance under Union Européenne de Football Association (UEFA), saw the end to 'quota systems' employed to restrict the number of 'foreign' players in a given match. For further reading see www.liv.ac.uk/footballindustry.

37 Antonioni and Cubbin, The Bosman Ruling and the Emergence of a Single Market in Soccer Talent, 157

38 The term coined by Ruud Gullit whilst working as a pundit for the BBC during Euro '96 in Winner, $A$ Sensual History of English Football, 8

39 ibid, 36

40 It is not then the authorisation of femininity, but that aesthetic 'adjustments' are instigated as a result of the implementation of governance sanctions. Also see Witt, Do Players React to Sanction Changes? Evidence from the English Premier League, 623

41 Witt, ibid, 635

42 The top female team participation sport in England and currently has $1.38 \mathrm{~m}$ women and girls up and down the country playing the game regularly. Source www.thefa.com, accessed $4^{\text {th }}$ October 2013.

43 Herdt, Third Sex, Third Gender, 25 
44 Azzarito et al, “... If I had a choice, I would... ” A feminist poststructuralist perspective on girls in physical education, 222; Cashmore, Making Sense of Sports, 12; Shilling, The Body and Social Theory, 10

45 Caudwell, Women's Experiences of Gender and Sexuality in Sport cited in Wagg, British Football and Social Exclusion, 2004, 130

46 Butler, Performative Acts and Gender Constitution, 19-20

47 Bhabha, The Location of Culture, 37

48 It will be interesting to see how this develops with the establishment of the Women's Super League.

49 In 1978, the parents of 12-year-old Theresa Bennett took the English FA to court for not allowing girls to play mixed football in a local league. Bennett lost the case, but the FA changed its rules in 1991 to allow under-11 mixed football (the English Schools Football Association (ESFA) also included girls' football in their legislation). Notably, this was 15 years after the Sex Discrimination Act (SDA) took effect.

50 Hargreaves, Sporting Females, 176

51 Lord Denning, Theresa Bennett vs. The Football Association, 4-5

52 Gartner, The Reasons for the Absence of Women's Football in England, 54

53 At the time of writing, 'the FA is pleased that the resolution to amend its Rules to extend mixed football in the U13 age group received approval from The FA Shareholders at the AGM today (25 May). The resolution was fully supported by The FA Board, FA Executive and FA Council and the result means that girls and boys will be able to play in the same teams at U12 and U13 level from next season (2011-12).' FA Statement on Mixed Football, $25^{\text {th }}$ May 2011. The raising of the age limit to under- 15 was sanctioned by the FA as of $17^{\text {th }}$ May 2013, 'The resolution to increase the mixed football age limit from U14s to U15s was approved on Thursday by The FA shareholders at their AGM after The FA Board, FA Executive and FA Council agreed the proposal,' from www.thefa.com, $17^{\text {th }}$ May 2013, accessed $15^{\text {th }}$ October 2013.

54 Skeggs looks at the generation of social capital that has an exchange value in Skeggs, Exchange, Value and Affect: Bourdieu and 'the Self', 75 
55 In 2008, The FA commissioned Brunel University to evaluate these trials to determine the key issues involved in mixed gender football (www.thefa.com, $10^{\text {th }}$ March 2010, accessed $7^{\text {th }}$ February 2012)

56 Caster Semenya was forced to undergo a 'sex verification test' because of her 'masculine' appearance.

This is indicative of the tension between athleticism and sexuality for female athletes. Presumably, failure to conform to a conventional standard of western femininity was licence for the International Olympic Committee (IOC) to conduct a series of demeaning 'gender verification' tests.

57 Herdt, Third Sex, Third Gender, 25

58 Caudwell, Women's Experiences of Gender and Sexuality in Sport cited in Wagg, British Football and Social Exclusion, 131

59 Mennesson, Hard Women and Soft Women: The Social Construction of Identities Among Female Boxers, 21-33

60 Thing, The Female Warrior: Meanings of Play-Aggressive Emotions in Sport, 276

61 In breaks and leisure time

62 Cahn, Coming on Strong, 184

63 Coddington, One of the Lads: Women Who Follow Football, 57; Fiske, op cit, 168; Caudwell, Women's Football in the United Kingdom: Theorising Gender and Unpacking the Butch Lesbian Image, 401; Cox and Thompson, Multiple Bodies: Sportswomen, Soccer and Sexuality, 7

64 Coed (mixed) soccer in the USA is bound by specific rules intended to 'equalise' gender differences onthe-field play. The outlawing of the slide tackle is a good example of this. It is considered one of the most potentially dangerous skills in football and is not allowed in most coed and women's leagues. See Henry and Comeaux, Gender Egalitarianism in Coed Sport, 280

65 Denzin and Lincoln, Handbook of Qualitative Research, 222-224; Harding, Whose Science? Whose Knowledge? Thinking from Women's Lives, 275-284 
66 Bhabha, The Location of Culture, 54

\section{References}

Antonioni, Peter, and Cubbin, John. 'The Bosman Ruling and the Emergence of a Single Market in Soccer Talent'. European Journal of Law and Economics, 9:2 (2000): 157-173

Azzarito, Laura, and Solomon, Melinda A. and Harrison, Louis. '... If I had a choice, I would...': A feminist poststructuralist perspective on girls in physical education'. Research Quarterly for Exercise and Sport, 77 (2006): 222-239

Bhabha, Homi K. The Location of Culture. London: New York: Routledge, 1994.

Bhabha, Homi K. 'The Commitment To Theory' New Formation: A Journal of Culture/Theory/Politics, Number 5, Summer (1988), 5-23

Butler, Judith. 'Performative Acts and Gender Constitution'. Conboy, Katie, and Medina, Nadia, and Stanbury, Sarah. (eds) Writing on the Body: Female Embodiment and Feminist Theory, New York: Columbia University Press, 1997.

Buzuvis, Erin E. 'Transgender Student-Athletes and Sex-Segregated Sport: Developing Policies of Inclusion for Intercollegiate and Interscholastic Athletics'. Seton Hall Journal of Sports \& Entertainment Law, Vol. 21, Western New England University School of Law Legal Studies Research Paper No. 11-2 (2011): 1-59 
Buzuvis, Erin E. 'Caster Semenya and the Myth of a Level Playing Field'. The Modern American, Vol. 6, Issue 2, Article 5, (2010): 36-42

Cahn, Susan, K. Coming on Strong: Gender and Sexuality in $21^{\text {st }}$ Century Women's Sport, Cambridge, MA: Harvard University Press, 2004.

Cashmore, Ellis. Making Sense of Sports (2 ${ }^{\text {nd }}$ edition). London: Routledge, 1996.

Caudwell, Jayne. 'Women's Football in the United Kingdom: Theorising Gender and Unpacking the Butch Lesbian Image'. Journal of Sport and Social Issues, Volume 23, No.4, November (1999): 390-402

Caudwell, Jayne. 'Women's Experiences of Gender and Sexuality in Football'. Wagg, S. (ed) British Football and Social Exclusion, London: Routledge, 2004.

Coddington, Anne. One of the Lads: Women Who Follow Football. Hammersmith London: Harper Collins, 1997.

Cox, Barbara and Thompson, Shona. 'Multiple Bodies: Sportswomen, Soccer and Sexuality'. International Review for the Sociology of Sport, 35/1, (2000): 5-20

Denzin, Norman K. and Lincoln, Yvonna S. (eds) Handbook of Qualitative Research (2 ${ }^{\text {nd }}$ edition). London: Sage, 2000.

Dunning, Eric. The Sociology of Sport. London: Frank Cass, 1971.

Fiske, John. Understanding Popular Culture. London: Routledge, 1989.

Gartner, Aggy. The Reasons for the Absence of Women's Football in England: Why Women's Football Has No Home in England, the Home of Football? Berlin: GRIN Verlag Publishers, 2007. Geertz, Clifford. 'Deep Play: Notes on the Balinese Cockfight'. Geertz, Clifford, The Interpretation of Cultures. New York: Basic Books, 1973.

Giulianotti, Richard. and Robertson, Roland. Globalisation and Football. London: Sage, 2009. Giulianotti, Richard. Football: A Sociology of the Global Game. Oxford: Polity, 1999.

Harding, Sandra. Whose Science? Whose Knowledge? Thinking from Women's Lives. Milton Keynes: OU Press, 1991.

Hargreaves, Jennifer. Sporting Females. London: Routledge, 1994.

Harris, John. 'Lie Back and Think of England: The Women of Euro 96'. Journal of Sport and Social Issues, Volume 23, No. 1, February (1999): 96-110

Henry, Jacques. M. and Comeaux, Howard. P. 'Gender Egalitarianism in Coed Sport: A Case Study of American Soccer'. International Review for the Sociology of Sport 34/3, (1999): 277-290 Herdt, Gilbert (ed). Third Sex, Third Gender: Beyond Sexual Dimorphism in Culture and History, New York: Zone Books, 1994.

Hester, Stephen, and Francis, David. 'Doing Data: The Local Organisation of the Sociological Interview'. British Journal of Sociology, 45, (1994): 675-95 
Ikas, K. and Wagner, G. (eds) Communicating in the Third Space. New York: Routledge, 2009. Lipset, Seymour Martin. American Exceptionalism: A Double Edged Sword. New York: W.W. Norton and Company, 2001.

Lord Denning, Theresa Bennett vs. The Football Association Limited and the Nottinghamshire Football Association (Unreported: Judgment of 28 July 1978)

Markovits, Andrei. S. and Hellerman, Steven. L. Offside: Soccer and American Exceptionalism. Princeton NJ; Oxford: Princeton University Press, 2001.

McLintock, Anne. Imperial Leather: Race, Gender and Sexuality in the Colonial Contest. New York; London: Routledge, 1995.

Mennesson, Christine. 'Hard Women and Soft Women: The Social Construction of Identities Among Female Boxers'. International Review for the Sociology of Sport, 35/1, (2000): 21-33

Pfister, Gertrud, Fasting, Kari, Scraton, Sheila, and Vasquez, Benilde. 'Women and Football - A Contradiction? The Beginnings of Women's Football in Four European Countries' in Mangan, James Anthony (ed). Sport in Europe: Politics, Class, Gender, London: Frank Cass Publishers, 1999.

Prasad, Pushkala. Crafting Qualitative Research: Working in the Post-Positivist Traditions. New York: M.E. Sharpe, 2005.

Sandvoss, Cornel. Fans: The Mirror of Consumption. Cambridge: Polity, 2005.

Sheringham, Sam. FA Announces Five-Year Plan to Boost Women's Football, www.bbc.co.uk. http://www.bbc.co.uk/sport/0/football/20071776

Shilling, Chris. The Body and Social Theory. London: Sage, 1993.

Skeggs, Beverley. 'Exchange, Value and Affect: Bourdieu and 'the Self'". Adkins, Lisa and Skeggs, Beverley. Feminism After Bourdieu, Oxford: Blackwell, 2004.

Stanley, Liz. and Wise, Sue. Breaking Out Again: Feminist Ontology and Epistemology. London: Routledge, 1993.

Thing, Lone Friis, 'The Female Warrior: Meanings of Play-Aggressive Emotions in Sport'. International Review for the Sociology of Sport, 36/3, (2001): 275-288

Walvin, James. The People's Game. Edinburgh: Mainstream Publishing, 1994.

Williams, Jane. A Game for Rough Girls? A History of Women's Football in Britain. London: Routledge, 2003.

Williams, John. and Woodhouse, Jackie. Can Play, Will Play? Women and Football in Britain. Sir Norman Chester Centre For Football Research, University of Leicester, April 1991.

Wilson, Jonathan. Inverting the Pyramid: A History of Football Tactics. London: Orion, 2008.

Winner, David. Those Feet: A Sensual History of English Football. London: Bloomsbury, 2005. 
Witt, Robert. 'Do Players React to Sanction Changes? Evidence from the English Premier League'. Scottish Journal of Political Economy, Vol. 52, No. 4, September 2005 